\title{
DotU expression is highly induced during in vivo infection and responsible for virulence and Hcp1 secretion in avian pathogenic Escherichia coli
}

\author{
Shaohui Wang ${ }^{1+}$, Jianjun Dai ${ }^{2+}$, Qingmei Meng ${ }^{1,2}$, Xiangan Han ${ }^{1}$, Yue Han ${ }^{1}$, Yichao Zhao ${ }^{1}$, \\ Denghui Yang ${ }^{1}$, Chan Ding ${ }^{1}$ and Shengqing $\mathrm{Yu}^{1}{ }^{*}$
}

'Shanghai Veterinary Research Institute, Chinese Academy of Agricultural Sciences, Shanghai, China

${ }^{2}$ College of Veterinary Medicine, Nanjing Agricultural University, Nanjing, China

\author{
Edited by: \\ Anna Norrby-Teglund, Karolinska \\ Institutet, Sweden \\ Reviewed by: \\ Li Xu, Cornell University, USA \\ Zuowei Wu, lowa State University, \\ USA

\section{*Correspondence:} \\ Shengqing Yu, Shanghai Veterinary \\ Research Institute, Chinese Academy \\ of Agricultural Sciences, Shanghai \\ 200241, China \\ e-mail:yus@shvri.ac.cn \\ ' Shaohui Wang and Jianjun Dai have \\ contributed equally to this work.
}

\begin{abstract}
Type VI secretion systems (T6SSs) contribute to pathogenicity in many pathogenic bacteria. Three distinguishable T6SS loci have been discovered in avian pathogenic Escherichia coli (APEC). The sequence of APEC T6SS2 locus is highly similar to the sequence of the newborn meningitis Escherichia coli (NMEC) RS218 T6SS locus, which might contribute to meningitis pathogenesis. However, little is known about the function of APECT6SS2. We showed that the APECT6SS2 component organelle trafficking protein (DotU) could elicit antibodies in infected ducks, suggesting that DotU might be involved in APEC pathogenicity. To investigate DotU in APEC pathogenesis, mutant and complemented strains were constructed and characterized. Inactivation of the APEC dotU gene attenuated virulence in ducks, diminished resistance to normal duck serum, and reduced survival in macrophage cells and ducks. Furthermore, deletion of the dot $U$ gene abolished hemolysincoregulated protein (Hcp) 1 secretion, leading to decreased interleukin (IL)-6 and IL-8 gene expression in HD-11 chicken macrophages. These functions were restored for the complementation strain. Our results demonstrated that DotU plays key roles in the APEC pathogenesis, Hcp1 secretion, and intracellular host response modulation.
\end{abstract}

Keywords: avian pathogenic Escherichia coli, type VI secretion system, DotU, secretion, virulence

\section{INTRODUCTION}

The protein secretion system is a common strategy for successful infection in hosts by Gram-negative bacteria (Saier, 2006). The type VI secretion system (T6SS) was first discovered in Vibrio cholerae (V. cholerae) in 2006 (Pukatzki et al., 2006; Records, 2011) and has been identified in more than one-fourth of all sequenced bacterial genomes (Filloux et al., 2008; Shrivastava and Mande, 2008; Boyer et al., 2009; Filloux, 2009). The T6SS contributes to the pathogenicity of many bacteria (Zheng and Leung, 2007; de Pace et al., 2010; Miyata et al., 2010; Mulder et al., 2012; Rosales-Reyes et al., 2012; Zhou et al., 2012; Ho etal., 2014) and to bacteriahost interactions or interbacterial interactions in non-pathogenic bacteria (Jani and Cotter, 2010; Basler et al., 2013).

Although the exact function of most T6SS proteins is not known, the majority are necessary for secretion of effector proteins including hemolysin-coregulated protein ( $\mathrm{Hcp})$, valine-glycine repeat protein $(\mathrm{VgrG}), \mathrm{ClpV}$, intracellular multiplication protein (IcmF) and organelle trafficking protein (DotU; Wu et al., 2008; Pukatzki et al., 2009). Hcp and VgrG are mutually dependent for secretion in V. cholerae, Edwardsiella tarda and enteroaggregative Escherichia coli (EAEC; Dudley et al., 2006; Pukatzki et al., 2007; Zheng and Leung, 2007), suggesting that Hcp and VgrG are secreted proteins and machine components. $\mathrm{ClpV}$ energizes secretion of effector proteins that form oligomeric complexes that enable ATP hydrolysis-dependent protein transport (Schlieker et al., 2005; Pukatzki etal., 2009). IcmF is a component of the
T6SS apparatus that is required for secretion by the T6SS and intracellular growth during infection. DotU stabilizes the secretion machinery and was essential for the intracellular life cycle and virulence of Francisella tularensis (Sexton et al., 2004; Zusman et al., 2004; Broms et al., 2012).

Systemic infections caused by avian pathogenic Escherichia coli (APEC) are economically devastating to poultry industries (Rodriguez-Siek et al., 2005b; Ewers et al., 2007). Moreover, APEC has a broad range of virulence factors similar to uropathogenic Escherichia coli (UPEC) and newborn meningitis Escherichia coli (NMEC), indicating that APEC may be a potential virulence gene reservoir for UPEC and NMEC (Wang and Kim, 2002; RodriguezSiek et al., 2005a; Moulin-Schouleur et al., 2006; Ewers et al., 2007; Johnson et al., 2008; Tivendale et al., 2010; Wang et al., 2011a). Three distinct and conserved T6SS loci, T6SS1, T6SS2 and T6SS3, are present in APEC genomes. T6SS1 and T6SS3 in APEC have homologs in EAEC. The T6SS2 in APEC is similar to the T6SS in NMEC RS218 (Ma et al., 2013). The T6SS1 core components (ClpV and Hcp) in the APEC strain SEPT362 are involved in adherence to and actin rearrangement in epithelial cells but are not involved in intramacrophage replication. The T6SS2 core components (Hcps) in NMEC RS218 coordinately function in steps of RS218 interaction with human brain microvascular endothelial cells (HBMECs) such as binding to and invasion of HBMECs, cytokine and chemokine release, and apoptosis. The T6SS3 locus lacks several key genes and is non-functional (de Pace et al., 2010; 
Zhou et al., 2012). However, the function of T6SS2 core genes in APEC remains unknown.

In this study, the $\operatorname{dot} U$-inactivated mutant and complementation strains were constructed from APEC strain DE719. The effects of DotU on normal duck serum resistance, cytopathogenicity, intramacrophage survival, Hcp1 secretion, and virulence were investigated.

\section{MATERIALS AND METHODS BACTERIAL STRAINS, PLASMIDS, AND GROWTH CONDITIONS}

Strains and plasmids are shown in Table 1. The wild-type APEC strain DE719 was isolated from a duck with clinical septicemia symptoms of colibacillosis in Jiangsu, China and identified as an APEC strain by phenotypic characters and virulence genes presence (Ewers et al., 2005). The serotype was identified by agglutination test with rabbit anti-Escherichia coli immune serum (Statens Serum Institut, Copenhagen, Denmark) and allele-specific PCR (Wang et al., 2014). Infection studies confirmed that APEC DE719 caused severe colibacillosis symptoms and high mortality in ducks and mice. Escherichia coli strain DH5 $\alpha$ was used for cloning and strain BL21 (DE3) was used for protein expression (Davanloo et al., 1984; Studier and Moffatt, 1986). All Escherichia coli strains were grown in Luria-Bertani (LB) medium at $37^{\circ} \mathrm{C}$ with aeration. When necessary, medium was supplemented with ampicillin (Amp; $100 \mu \mathrm{g} / \mathrm{mL}$ ) or chloramphenicol $(\mathrm{Cm} ; 30 \mu \mathrm{g} / \mathrm{mL})$.

\section{EXPRESSION AND PURIFICATION OF RECOMBINANT DotU, Hcp1, AND Hcp2 PROTEINS}

DNA manipulation and transformation were performed using standard methods. All restriction enzymes were purchased from
TaKaRa (Dalian, China). Plasmid DNA was isolated using High Pure Plasmid Miniprep kits (Invitrogen, San Diego, CA, USA). PCR product purification and DNA extractions from agarose gels used Agarose Gel DNA Fragment Recovery Kits (TaKaRa) according to the manufacturer's guidelines. Open reading frames (ORFs) of $\operatorname{dot} U, h c p 1$, and $h c p 2$ were amplified with primers in Table 2 and subcloned into pET28a (+) vector (Novagen, Madison, WI, USA). Recombinant plasmids were transformed into competent Escherichia coli BL21 (DE3) and proteins were expressed by isopropyl-beta-D-thiogalactopyranoside (IPTG) induction at a final concentration of $1 \mathrm{mM}$. Fusion proteins were purified using HisTrap HP columns (GE Healthcare, Shanghai, China) according to the manufacturer's guidelines. Final protein concentrations were determined by Bradford method using SmartSpec3000 (BioRad). Polyclonal antibodies were produced in New Zealand White rabbits as described previously (Dai et al., 2010; Wang et al., 2011a, 2012).

\section{CONSTRUCTION OF MUTANT AND COMPLEMENTATION STRAINS}

The isogenic mutants DE719 $\Delta$ dotU and DE719 $\Delta$ T6SS2 were constructed according to the method of Datsenko and Wanner (2000). Chloramphenicol resistance cassettes flanked by upstream and downstream sequences of $\operatorname{dot} U$ or the T6SS2 locus were amplified and transformed into the APEC DE719-containing lambda red recombinase expression plasmid pKD46. After electroporation, samples were incubated at $37^{\circ} \mathrm{C}$ for $1 \mathrm{~h}$ in super optimal broth with catabolite repression broth and plated on LB agar with chloramphenicol. Resistant mutants were confirmed by PCR amplification and sequence analysis using primers $\mathrm{C} 1$ and $\mathrm{C} 2$ (Datsenko and Wanner, 2000) combined with primers flanking

Table 1 | Bacterial strains and plasmids used in this study.

\begin{tabular}{|c|c|c|}
\hline Strains or plasmids & Characteristics & Reference \\
\hline \multicolumn{3}{|l|}{ Strain } \\
\hline DE719 & $\mathrm{O} 2: \mathrm{K} 1$ & \\
\hline DE719 $\Delta$ dotU & dotU deletion mutant in DE719 & This study \\
\hline DE719C $\Delta$ dotU & DE719 $\Delta$ dotU with plasmid pSTV28-dotU & This study \\
\hline DE719 $\Delta$ T6SS2 & T6SS2 deletion mutant in DE719 & This study \\
\hline DE719 $\Delta$ hcp1 & hcp1 deletion mutant in DE719 & This study \\
\hline $\mathrm{DH} 5 \alpha$ & $\mathrm{F}-, \Delta(\operatorname{lacZYA}-\arg F) \cup 169$, recA1, endA1, hsdR17(rk-, mk+), phoA, supE44, $\lambda-$ & TIANGEN \\
\hline BL21 (DE3) & $\mathrm{F}-$, ompt, hsdS $\left(r_{B}^{-} m_{B}^{-}\right) \mathrm{gal}, \mathrm{dcm}(\mathrm{DE} 3)$ & TIANGEN \\
\hline \multicolumn{3}{|l|}{ Plasmid } \\
\hline pET28a $(+)$ & Kan, F1 origin, His tag & Novagen \\
\hline pET28a-dotU & pET28a $(+)$ carrying $\operatorname{dot} U$ gene & This study \\
\hline pET28a-hcp1 & pET28a (+) carrying hcp1 gene & This study \\
\hline pET28a-hcp2 & pET28a $(+)$ carrying hcp2 gene & This study \\
\hline pMD 18-T Vector & Amp, lacZ & Takara \\
\hline pSTV28 & Cm, lacZ & Takara \\
\hline pSTV28-dotU & pSTV28 derivative harboring dotU & This study \\
\hline pKD46 & Amp; expresses $\lambda$ red recombinase & Datsenko and Wanner (2000) \\
\hline pKD3 & Cm gene, template plasmid & Datsenko and Wanner (2000) \\
\hline pCP20 & Cm, Amp, yeast Flp recombinase gene, FLP & Datsenko and Wanner (2000) \\
\hline
\end{tabular}


Table 2 | Primers used in this study.

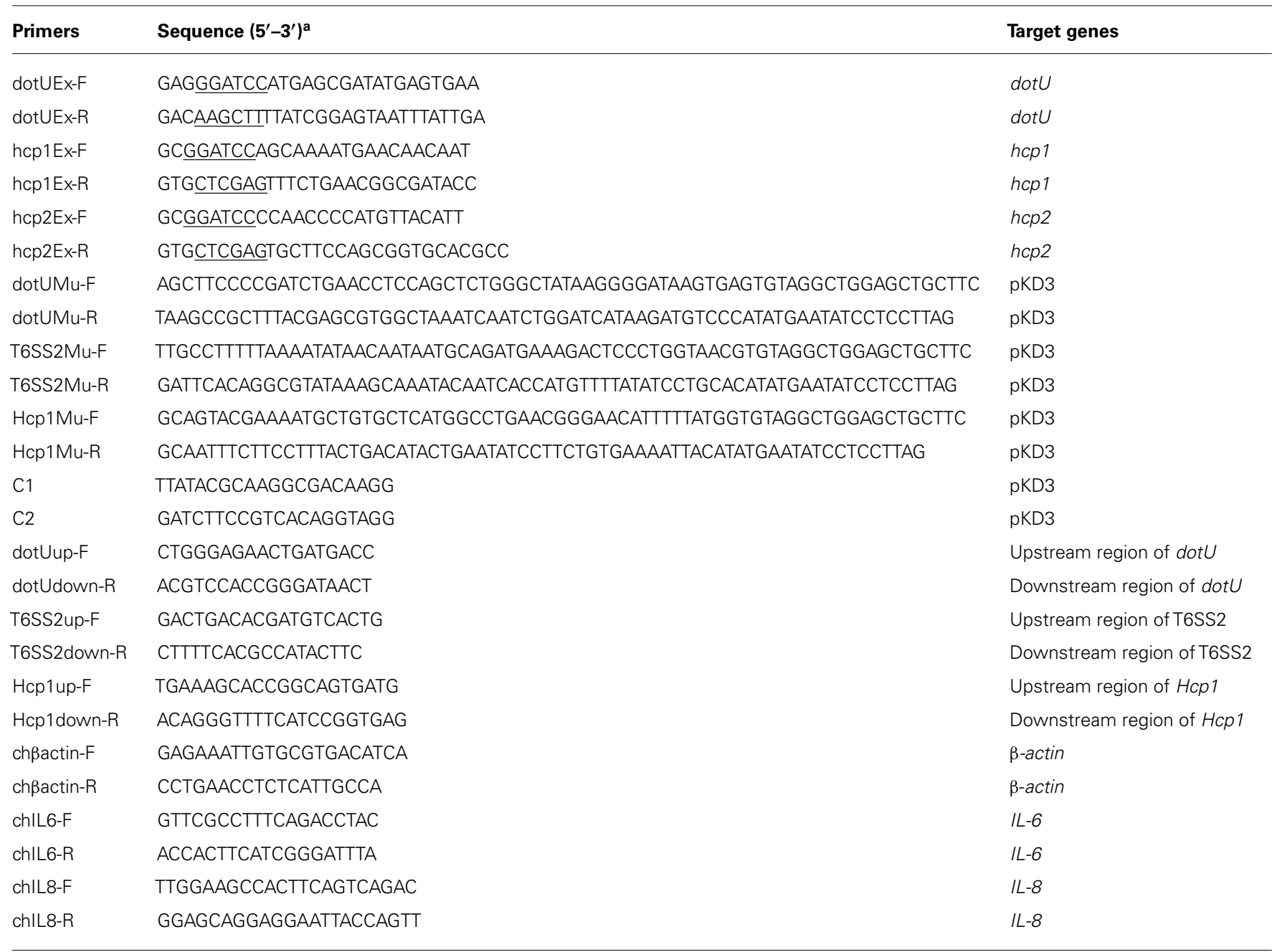

${ }^{a}$ Restriction sites are underlined.

the $\operatorname{dot} U$ or T6SS2 region. The chloramphenicol resistance cassette was cured by transforming with plasmid pCP20 and selecting for chloramphenicol sensitive strain.

The upstream region of the dotU ORF contained no promoter, so the $\operatorname{dot} U$ gene was complemented in trans by cloning into plasmid pSTV28 using primers dotUEx-F and dotUEx-R (Table 2). The resulting plasmid pSTV28-dotU was transformed into DE719 $\Delta$ dotU to generate strain DE719C $\Delta$ dotU. The complementation strain was identified by PCR. To detect the effect of DotU on growth rate, growth kinetics of strains were determined.

\section{DUCK SERA PREPARATION AND ENZYME-LINKED IMMUNOSORBENT ASSAYS}

To investigate if anti-DotU antibody was elicited during APEC infection, APEC DE719-infected duck sera, DE719 $\Delta$ dotU pre-adsorbed anti-DE719 sera and inactivated APEC DE719immunized duck sera were titered using an enzyme-linked immunosorbent assay (ELISA). APEC DE719-infected duck sera were produced as described previously (Zhuge et al., 2013). Ducks were infected intratracheally with live APEC DE719 at $5 \times 10^{6}$ colony forming units (CFUs) twice over a 2-week interval. At 10 days after the second infection, serum was collected from the survivors. Pre-adsorbed APEC DE719-infected duck sera were prepared by adsorption to DE719 $\Delta \operatorname{dot} U$ bacteria at $37^{\circ} \mathrm{C}$ for $2 \mathrm{~h}$. Immunized duck sera were obtained from 8 ducks vaccinated twice with ISA 71VG (Seppic, France) emulsified with formalininactivated APEC DE7 19 cells. Negative sera were obtained from 8 ducks inoculated with phosphate-buffered saline (PBS). Microtiter plates were overnight coated at $4^{\circ} \mathrm{C}$ with purified recombinant DotU at $0.5 \mu \mathrm{g} /$ well. Wells were washed twice with PBST (PBS with 0.05\% Tween-20) and blocked with PBST-5\% skim milk for $1 \mathrm{~h}$. After washing with PBST, duck antisera were 2-fold serial diluted, starting at 1:8 and added to ELISA plate wells for $2 \mathrm{~h}$. Wells were washed three times and horseradish peroxidase (HRP)-conjugated anti-duck IgG (KPL, Gaithersburg, MD, USA) was used as the secondary antibody. Antibody against DotU was visualized by adding $100 \mu \mathrm{L} 3,3^{\prime}, 5,5^{\prime}$-tetramethyl benzidine (Tiangen, Beijing, China), stopping with $100 \mu \mathrm{L} 2 \mathrm{M} \mathrm{H}_{2} \mathrm{SO}_{4}$. Absorbance at $450 \mathrm{~nm}$ was determined with a plate reader (Bio-Tek Instruments, Winooski, VT, USA). Titers were defined as the reciprocal of the highest 


\section{A}

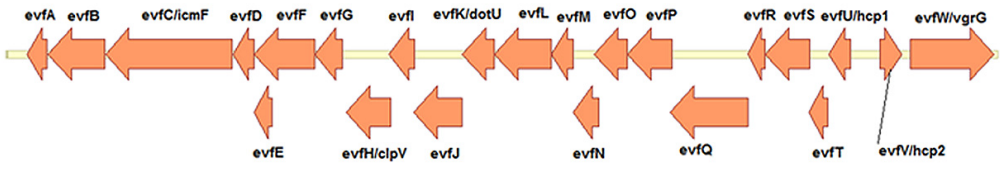

B

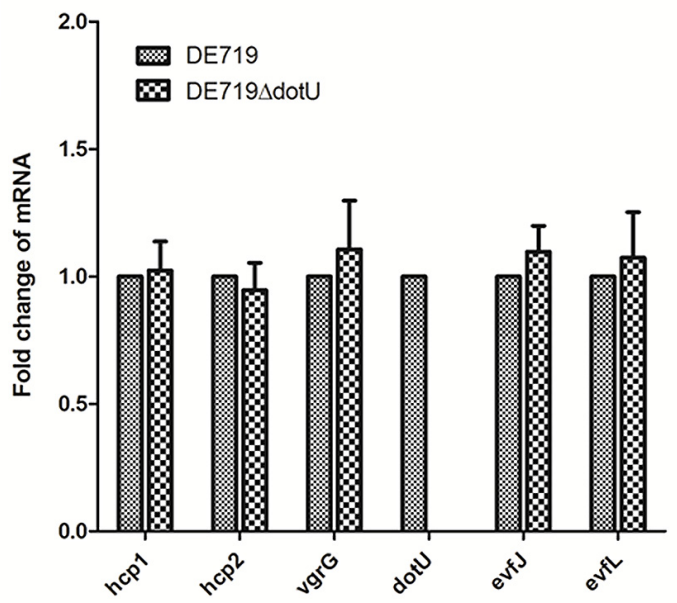

FIGURE 1 | (A) Schematic diagram of the genetic organization of APEC DE719 T6SS2 gene clusters. The T6SS2 whole-gene cluster of ORFs with different direction is shown. (B) Quantification of T6SS2 core genes expression. Transcript levels of $h c p 1, h c p 2, \operatorname{vgrG}$, dotU, evfJ, and evfL in DE719 and DE719 $\Delta$ dotU analyzed by qRT-PCR. Data were normalized to the housekeeping gene $d n a E$ and shown as fold changes.
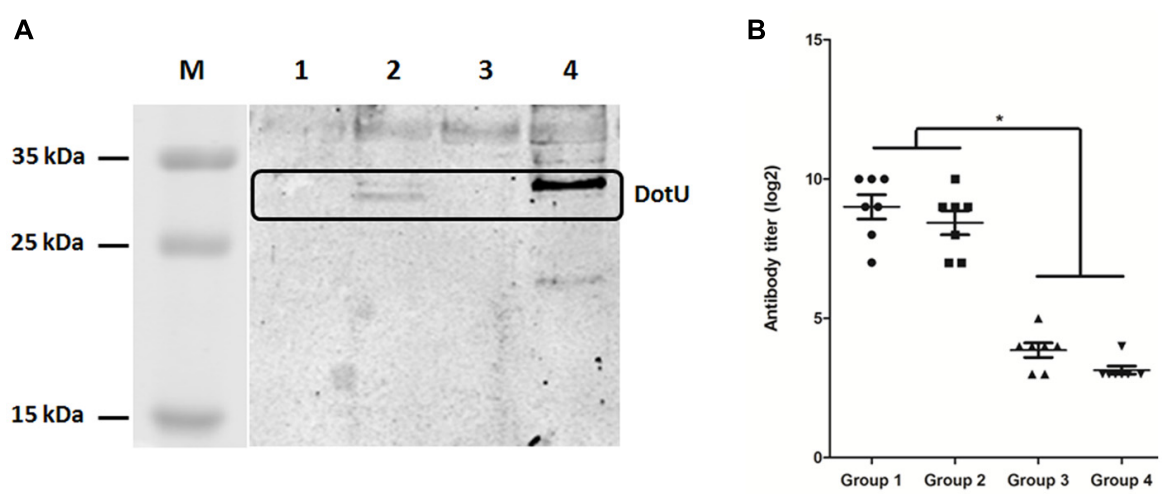

FIGURE 2 | DotU expression and anti-DotU antibody production. (A) Western blotting for DotU expression using duck anti-DotU. Lane M, prestained protein marker; Lane 1, DE719 doto cell lysate; Lane 2, DE719C $\Delta$ dotU cell lysate; Lane 3, DE719 cell lysate; Lane 4, purified recombinant DotU. (B) ELISA for anti-DotU titers in duck sera. Group 1, APEC DE719 infected duck sera; Group 2, APEC DE719 infected duck sera pre-adsorbed with DE719 $\Delta$ dotU; Group 3, Duck sera induced by inactivated APEC DE719 immunization; Group 4, Negative sera from ducks inoculated with PBS. ${ }^{*} p<0.05$. dilution of serum producing a 2.1-fold ratio value above negative serum.

\section{PREPARATION AND ANALYSIS OF SECRETORY PROTEINS}

Secretory proteins were prepared as described previously with modifications (Zhou etal., 2012). Overnight bacterial cultures were diluted 1:100 into fresh LB medium and grown to logarithemic phase at $37^{\circ} \mathrm{C}$ with shaking. Bacteria were harvested and centrifuged at $10,000 \times g$ for $15 \mathrm{~min}$ at $4^{\circ} \mathrm{C}$. Supernatants were collected and filtered through a $0.22 \mu \mathrm{m}$ membrane to remove bacterial cell contamination. Secretory proteins were precipitated from the supernatant using 10\% trichloroacetic acid and washed with acetone. Secretory proteins quality was verified by Western blotting for the absence of the cytosolic marker cAMP receptor protein (CRP) using anti-CRP antibody (Santa Cruz, CA, USA).

Secretory proteins were analyzed as described (Wang et al., 2011a,b). Briefly, protein samples were subjected to sodium dodecyl sulfate-polyacrylamide gel electrophoresis (SDS-PAGE) 


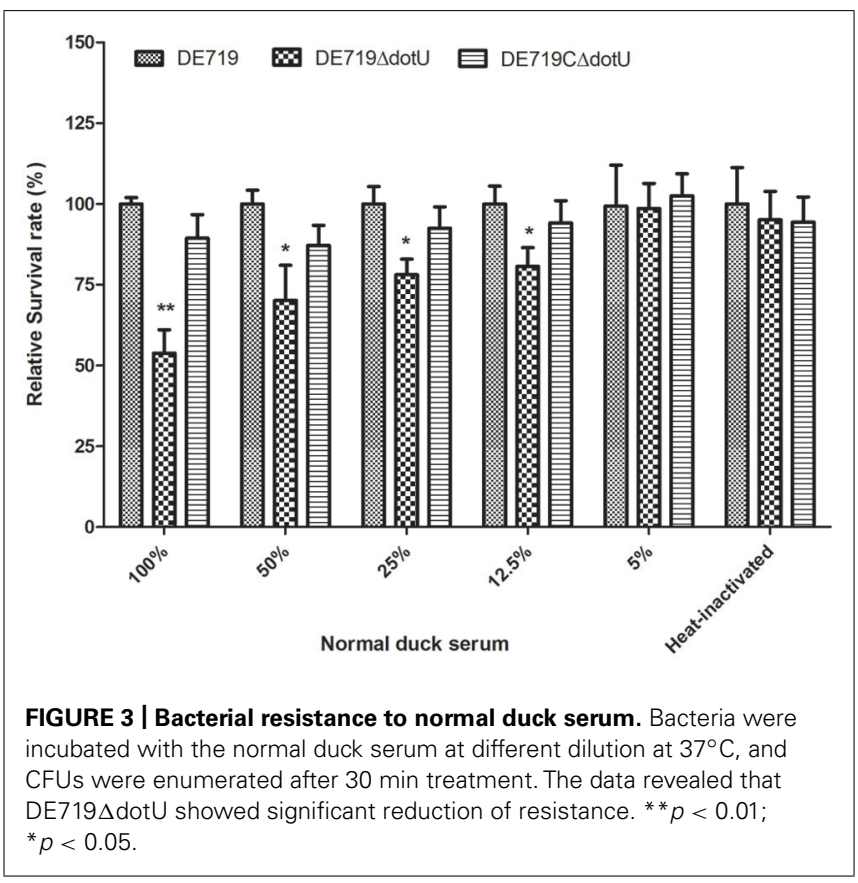

and transferred onto a polyvinylidene fluoride membrane (Amersham Pharmacia Biotech, Piscataway, NJ, USA). Anti-Hcp1, anti-Hcp2 or anti-CRP antibody were used as primary antibodies. IRDye 800CW-conjugated donkey anti-rabbit polyclonal antibody (LI-COR) was the secondary antibody. Blots were visualized with the Odyssey Two-Color Infrared Imaging System (LI-COR).

\section{BACTERIAL RESISTANCE TO NORMAL DUCK SERUM}

Normal duck serum was obtained from healthy 10-day-old Cherry-Valley ducks. No APEC antibodies were detected using ELISA. Bactericidal assays were performed in 96-well plates as described previously with some modifications (Gao et al., 2013). Briefly, normal duck serum was diluted to $5,12.5,25$, and $50 \%$ in PBS. Bacteria were added to sera at different dilutions, incubated at $37^{\circ} \mathrm{C}$ for $30 \mathrm{~min}$. Then, bacteria were enumerated by plating on LB agar plates. Heat-inactivated normal duck serum was used as a control.

\section{BACTERIAL ADHESION AND INVASION ASSAYS}

Bacterial adhesion and invasion assays were as described previously (Wang et al., 2011a; Zhuge et al., 2013). Chicken embryo fibroblast DF-1 cell monolayers were washed with Dulbecco's modiszfied Eagle's medium (DMEM) without fetal bovine serum (FBS) and infected with bacteria at a multiplicity of infection (MOI) of 100 for $2 \mathrm{~h}$ at $37^{\circ} \mathrm{C}$ under $5 \% \mathrm{CO}_{2}$. After washing with PBS, cells were lysed with $0.5 \%$ Triton X-100 and bacteria were counted by plating on LB agar plates. For invasion assays, cell cultures, bacterial infection, and bacterial counting were as described for bacterial adhesion assays. Cells were treated with DMEM containing gentamicin $(100 \mu \mathrm{g} / \mathrm{mL})$ for $1 \mathrm{~h}$ to kill extracellular bacteria. Monolayers were washed and lysed with $0.5 \%$ Triton X-100. Released bacteria were counted by plating on LB agar plates. Negative control wells containing DF-1 cells only were used in all experiments. Assays were performed three times in triplicate.

\section{INTRACELLULAR SURVIVAL ASSAYS}

To determine bacterial intracellular survival capacity, chicken macrophage HD-11 cells were infected with bacteria as described for invasion assays. After $1 \mathrm{~h}$ of infection, cells were washed and treated with DMEM containing gentamicin $(100 \mu \mathrm{g} / \mathrm{mL})$ for $1 \mathrm{~h}$ to kill extracellular bacteria. Released bacteria were defined as bacteria initially invasive to HD-11 cells. To determine intracellular survival, cells were grown in DMEM containing $10 \mu \mathrm{g} / \mathrm{mL}$ gentamicin for 6,12 , or $24 \mathrm{~h}$ before lysis of cultured cells. Intracellular survival was expressed as change ( $n$-fold) in bacterial number at a given time point relative to initial invasive bacteria.

\section{ANIMAL EXPERIMENTS}

Animal experiments were carried out in accordance with guidelines of the Association for Assessment and Accreditation of Laboratory Animal Care International (AAALAC). The animal study protocol (13-05) was approved by the Animal Care and Use Committee of the Shanghai Veterinary Research Institute, Chinese Academy of Agricultural Sciences (CAAS), China.

To determine the effect of $\operatorname{dot} U$ on bacterial virulence, groups of eight 7-day-old ducks were inoculated intratracheally with bacterial suspensions of DE719, DE719 $\Delta$ dotU, or DE719C $\Delta \operatorname{dotU}$ at $10^{7}$ CFU. Ducks inoculated intratracheally with PBS were used as negative controls. Mortality was monitored daily until 7 days after infection. Experiments were repeated three times.

Bacterial colonization was determined during systemic infections as described previously (Antao etal., 2009; Wang etal., 2011a,b). Briefly, groups of eight 7-day-old ducks were infected intratracheally with a bacterial suspension containing $10^{8}$ CFUs. At $24 \mathrm{~h}$ after infection, ducks were euthanized and dissected. Organs were homogenized, diluted and plated onto LB agar to determine bacterial numbers.

\section{QUANTITATION OF CYTOKINES EXPRESSION LEVELS IN HD-11 CELLS}

The mRNA levels of cellular inflammatory cytokines in HD-11 cells infected with APEC strains were investigated by quantitative real-time reverse transcription PCR (qRT-PCR). In brief, total RNA was isolated from bacteria infected HD-11 cells using TRIZol ${ }^{\circledR}$ reagent (Invitrogen). Contaminating DNA was removed from the samples with RNase-free DNase I (TaKaRa). cDNA synthesis was performed using the PrimeScript ${ }^{\circledR}$ RT reagent kit (TaKaRa) according to the manufacturer's protocol. qRT-PCR was performed using SYBR ${ }^{\circledR}$ Premix Ex Taq $^{\text {TM }}$ (TaKaRa) and gene-specific primers (Table 2). The relative gene expression was normalized to the $\beta$-actin gene via the $\Delta \Delta \mathrm{Ct}$ method (Livak and Schmittgen, 2001). All samples were calibrated to levels of gene expression of DE719 infected HD-11 cells. PCR efficiency (>90\%) for each of the genes was verified via standard dilution curves. The assay was performed in duplicate and repeated three times.

\section{STATISTICAL ANALYSES}

Statistical analyses used the GraphPad Software package (GraphPad Software, La Jolla, CA, USA). One-way analysis of variance (ANOVA) was used for analysis of adhesion assay data, and two-way ANOVA was performed for survival assays and qRTPCR results. Animal infection data were analyzed using the non-parametric Mann-Whitney U-test. Survival curves were 

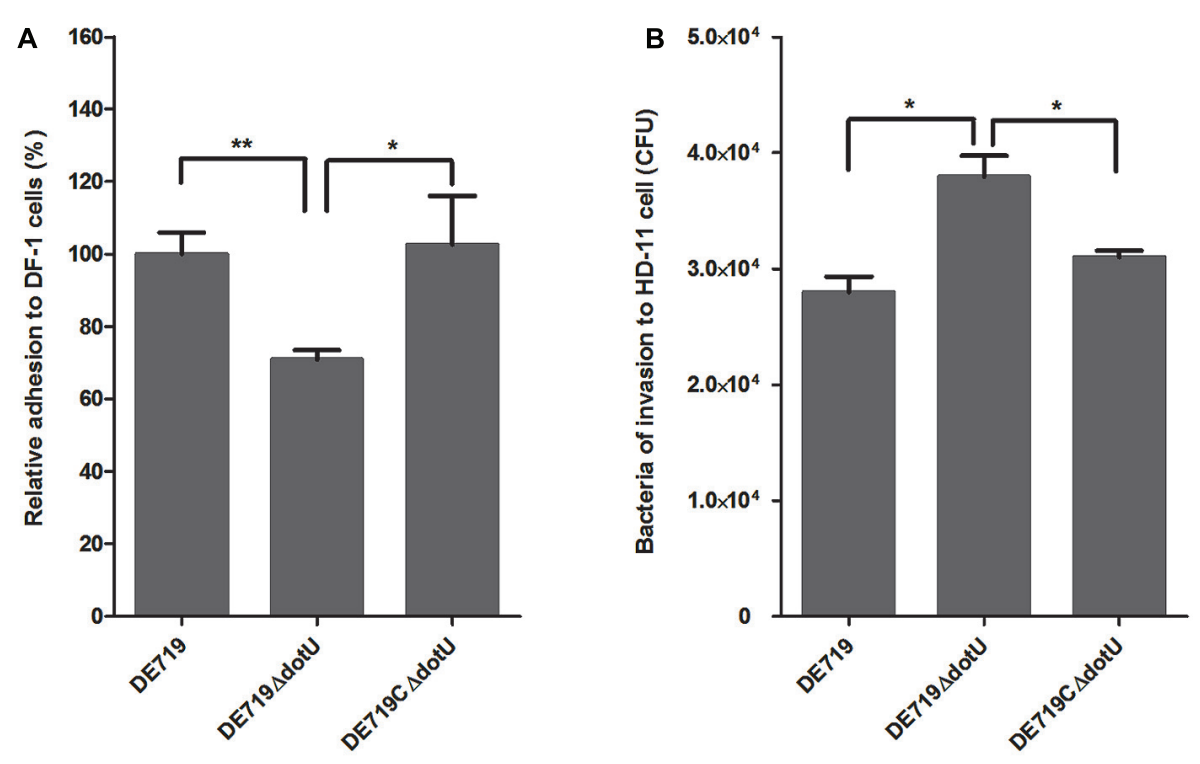

C

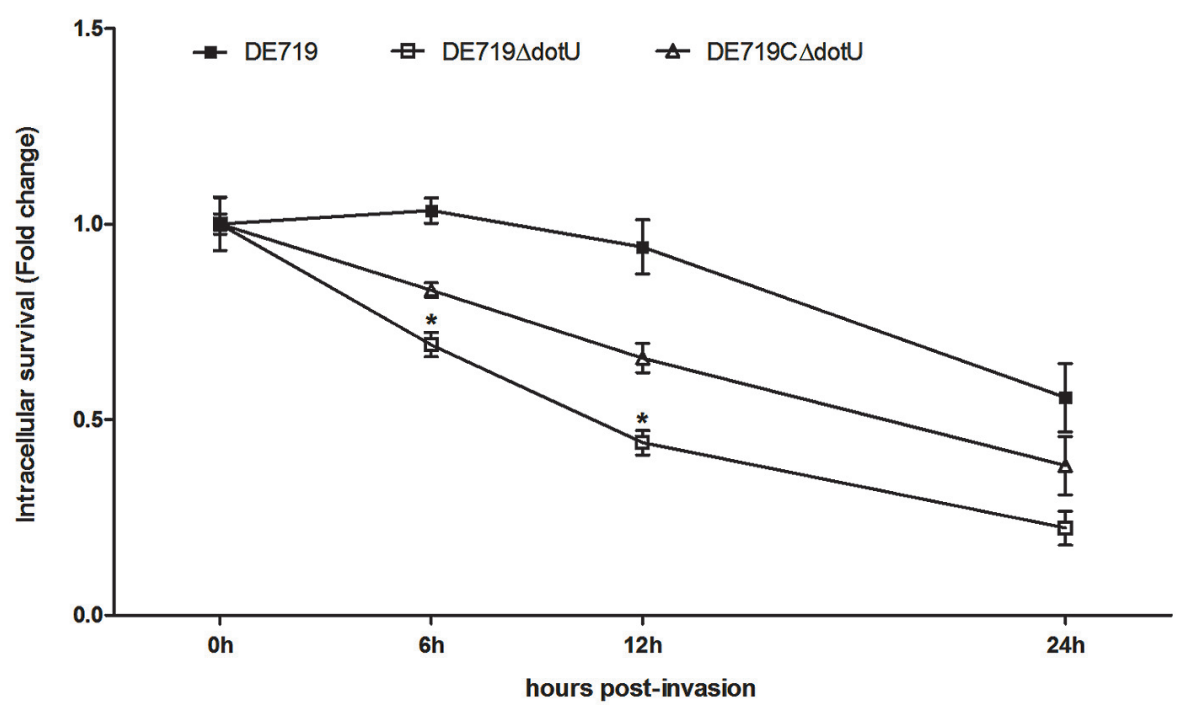

FIGURE 4 | Bacterial adhesion, invasion, and intracellular survival assays. (A) Adhesion assays performed on DF-1 cells. Values are average of three independent experiments. Error bars indicate standard deviations. One-way ANOVA was performed for statistical significance. ${ }^{*} p<0.01 ;{ }^{*} p<0.05$. (B) Invasion assays with chicken macrophage HD-11 cells. Values are average of three independent experiments. Error bars indicate standard deviations. One-way ANOVA was performed for significance. ${ }^{*} p<0.05$. (C) Intracellular survival in chicken macrophage HD-11 cells, expressed as fold change in bacterial number at 6,12 , and $24 \mathrm{~h}$ relative to initial invasion. ${ }^{*} p<0.05$, compared with DE719. created by the Kaplan-Meier method using the product limit method and compared by the log-rank (Mantel-Cox) test. Figures show mean values. Statistical significance was established at $p<0.05$.

\section{RESULTS}

\section{DELETION OF $\operatorname{dotU}$ AND T6SS2 DOES NOT AFFECT GROWTH KINETICS AND APEC DE719 SWARMING}

The mutant strains DE719 $\Delta$ dotU, DE719 $\Delta$ T6SS2, and complementation strain DE719C $\Delta$ dotU were generated and confirmed by PCR. No significant growth defect was observed among them during growth in LB medium (data not shown). DE719 $\Delta$ dotU and DE719 $\triangle$ T6SS2 mutants migration was similar to the wild-type DE719 strain on swarming agar plates, indicating that motility was not affected by disruption of DotU and T6SS2 (data not shown).

Genome sequence analysis showed that ORF order and component genes of T6SS2 in APEC DE719 were the same as in NMEC RS218 (Figure 1A). To determine whether $\operatorname{dot} U$ mutation had a polar effect on upstream or downstream genes, transcription levels of $h c p 1, h c p 2, v g r G$, evfJ, and evfL of the DE719 and DE719 $\Delta \operatorname{dot} U$ were analyzed by qRT-PCR. Deletion of the $\operatorname{dot} U$ gene had no 

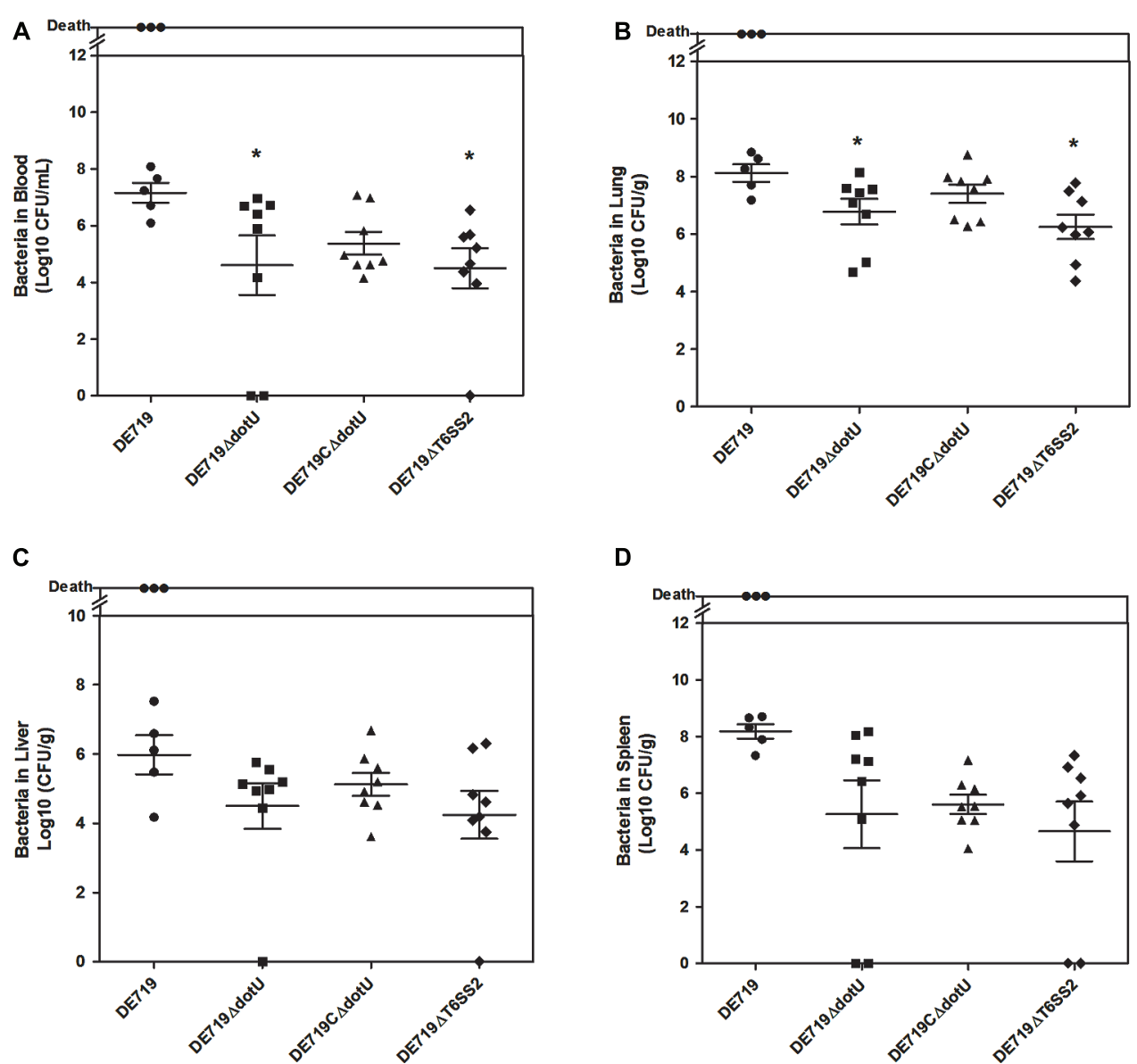

FIGURE 5 | Animal systemic infection experiments. Groups of eight 7-day-old ducks were intratracheally infected with $10^{8} \mathrm{CFU}$ bacteria. Bacteria were recovered from blood (A), lungs (B), livers (C), and spleens (D) at $24 \mathrm{~h}$ post-infection. ${ }^{*} p<0.05$ compared with DE719. Non-parametric Mann-Whitney U-test was carried out for statistical significance.

influence on expression of the upstream and downstream genes in T6SS2 (Figure 1B).

\section{DotU INDUCTION AND ANTI-DotU ANTIBODY PRODUCTION IN DUCKS}

Analysis by qRT-PCR revealed considerably lower transcription of $\operatorname{dot} U$ in LB-cultured DE719 compared to the housekeeping gene dnaE $\left(\Delta \mathrm{Ct}=4.77 \pm 0.77, \mathrm{Ct}_{\text {dnaE }}=26.14 \pm 1.49\right.$, $\left.\mathrm{Ct}_{\text {dot } U}=30.91 \pm 0.79\right)$. Thus, western blotting was performed with anti-DotU serum, which showed that expected protein bands of DotU were detected for complementation strain DE719C $\Delta \operatorname{dot} U$. However, there were no detectable bands for wildtype and mutant strains (Figure 2A). To further investigate DotU expression in vivo, ELISA was used to measure DotU antibody titers in ducks. Anti-DotU titers in APEC DE719-infected ducks was $2^{9}$ on average. In addition, pre-adsorbed sera by DE719 $\Delta$ dotU cells produced similar anti-DotU titer to APEC DE719 infected duck sera, suggesting the antibody is specific to the DotU, not a background reading. Contrastively, duck sera induced by inactived APEC DE7 19 immunization yielded very low anti-DotU titer, which is similar to the negative sera (Figure 2B). Thus, the results showed that DotU was highly induced during APEC infection.

\section{DotU IS INVOLVED IN BACTERIAL RESISTANCE TO NORMAL DUCK SERUM KILLING}

Avian pathogenic Escherichia coli causes typical avian colibacillosis, with bacteria invading air sacs, blood, pericardial fluid, and the typical fibrinous lesions. Thus, resistance to serum is associated with APEC pathogenicity. Bactericidal assays revealed that the mutant strain DE719 $\Delta$ dotU had lower resistance to normal duck serum than the wild-type strain DE719. Resistance was restored in the complementation strain (Figure 3). These results indicated that DotU was involved in bacterial serum resistance.

\section{DotU FACILITATES APEC ADHESION TO DF-1 CELLS}

DotU effects on bacterial adhesion and invasion to avian cell lines were determined. DF-1 cells were infected with DE719, DE719 $\Delta$ dotU, and the complementation strain DE719CAdotU. Numbers of bacteria adhering to and invading DF-1 cells were determined. No significant differences were observed among the bacterial strains for invasion capacity, indicating that DotU did not affect APEC invasion of DF-1 cells (data not shown). However, adherence of the mutant strain DE719 $\Delta$ dotU was significantly reduced compared with the wild-type strain DE719 


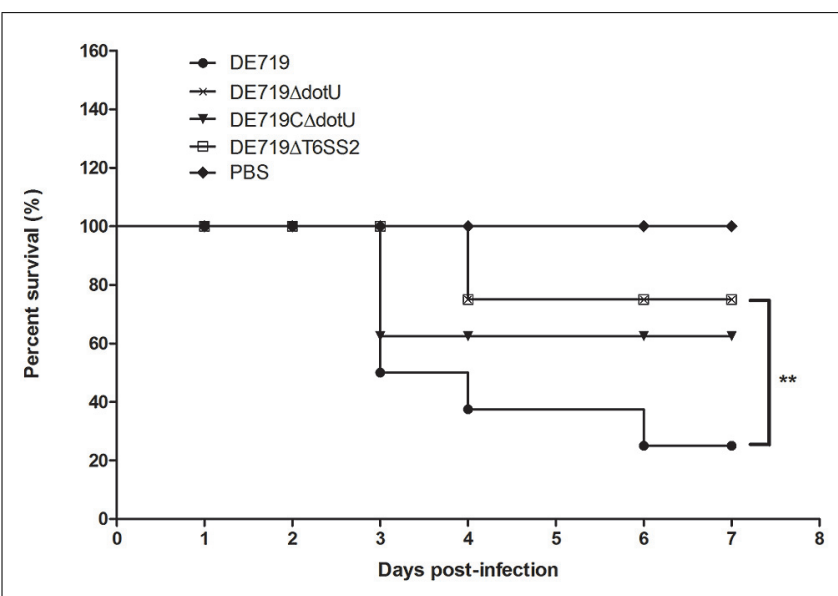

FIGURE 6 | Determination of bacterial virulence. 7-day-old ducks were inoculated intratracheally with DE719, DE719 1 dotU, DE719C $\Delta$ dotU, or DE719 $\Delta$ T6SS2 suspensions at $10^{7}$ colony-forming units (CFUs). Negative controls were injected with PBS. Survival was monitored until 7 days post-infection. ${ }^{*} p<0.01$, compared with DE719.

$(p<0.01$; Figure 4A). Adhesion capacity was restored in the complementation strain DE719C $\Delta$ dotU. These results suggested that DotU plays a role on adherence of APEC to DF-1 cells.

\section{DotU CONTRIBUTES TO INTRACELLULAR SURVIVAL IN MACROPHAGES}

Systemic dissemination is dependent on survival within phagocytic cells. Therefore, DotU involvement in intracellular survival and replication was assessed at $0,6,12$, and $24 \mathrm{~h}$ post-invasion of HD-11 cells. Compared to DF-1, the mutant strain DE719 $\Delta$ dotU exhibited significantly increased invasiveness of macrophage HD-11 cells compared to wild-type and the complementation strain $(p<0.05$; Figure 4B). However, the wild-type strain had a higher intracellular survival rate than the mutant strain DE719 $\Delta \operatorname{dot} U$ at all time points tested. Partial complementation for intracellular survival capacity was observed for strain DE719C $\Delta \operatorname{dot} U$ (Figure 4C). Thus, DotU was essential for APEC intramacrophage survival.

\section{DotU AND T6SS2 AFFECT BACTERIAL COLONIZATION AND SURVIVAL DURING INFECTION IN VIVO}

To determine the role of DotU in vivo infection, ducks were infected intratracheally with DE719, DE719 $\Delta \operatorname{dot} U$, DE719C $\Delta$ dotU, and DE719 $\Delta$ T6SS2. Bacterial loads in blood, lung, liver, and spleen were investigated at $24 \mathrm{~h}$ postinfection. Colonization of mutant strains DE719 $\Delta$ dotU and DE719 $\triangle$ T6SS2 in the blood and lung were significantly reduced compared to wild-type DE719 $(p<0.05)$. DE719C $\Delta \operatorname{dot} U$ had recovered bacterial colonization capacity (Figures 5A,B). Bacterial loads in the liver and spleen of infected ducks were not significantly different among DE719, DE719 $\Delta$ dotU, DE719C $\Delta$ dotU, and DE719 $\Delta$ T6SS2 $(p>0.05$; Figures 5C,D). These results indicated that DotU and T6SS2 were involved in colonization and survival during infection in vivo.

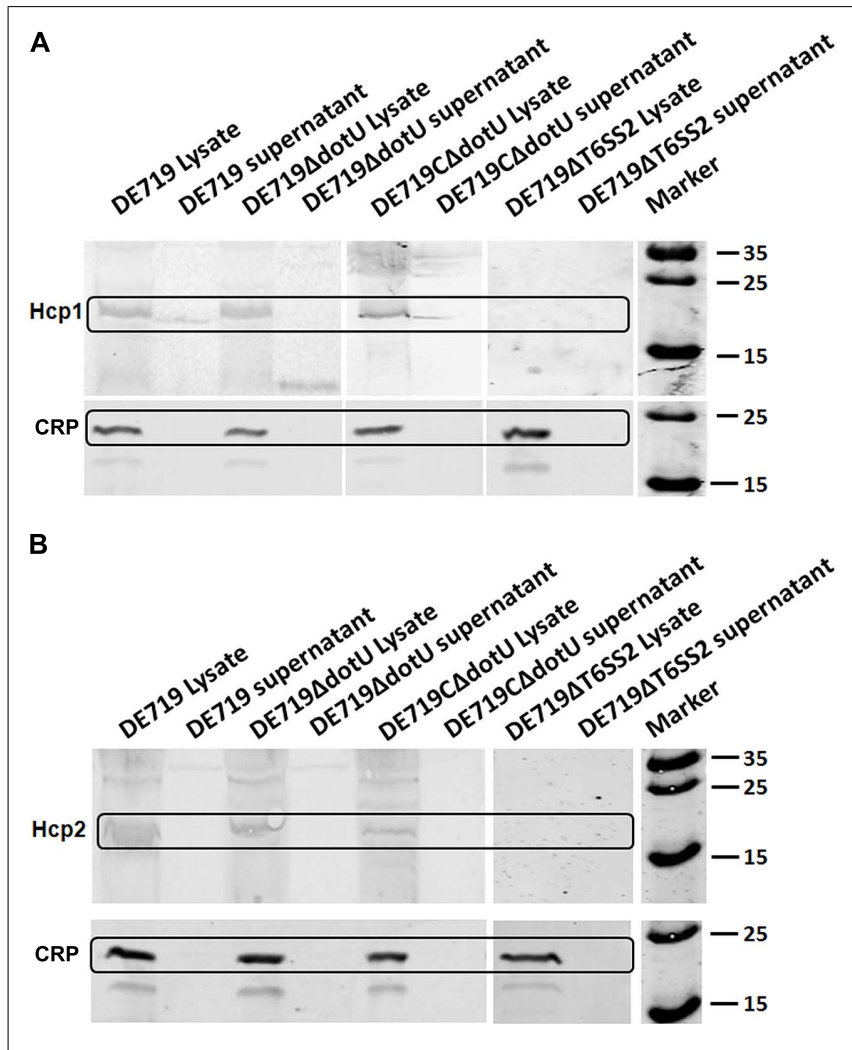

FIGURE 7 | DotU was essential for Hcp1 secretion by T6SS2 in APEC. (A) Hcp1 secretion in APEC supernatants by western blot using anti-Hcp1. Hcp1 protein was detected at the expected size in culture supernatants of DE719 and DE719C $\Delta$ dotU. No Hcp1 secretion was detected in supernatants of DE719 $\Delta$ dotU and DE719 $\Delta$ T6SS2. (B) No Hcp2 was detectable in supernatants of DE719 and DE719C $\Delta$ dotU or lysates and supernatant of DE719 $\Delta$ T6SS2. CRP was the cytoplasmic protein marker.

\section{DELETION OF DotU AND T6SS2 ATTENUATES APEC STRAIN DE719 VIRULENCE IN VIVO}

To investigate if DotU or T6SS2 affected bacterial virulence, groups of eight ducks were infected with bacteria at $1 \times 10^{7}$ CFU. Mortality was 75\% (6/8) for infection with DE719, 12.5\%

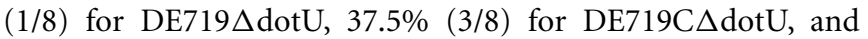
$12.5 \%(1 / 8)$ for DE719 $\Delta$ T6SS2 (Figure 6). These results indicated that inactivation of $\operatorname{dot} U$ or T6SS2 locus attenuated virulence in ducks. Virulence was partly restored in the complementation strain. These results provided evidence that DotU and T6SS2 were important virulence factors in APEC strains.

\section{DotU WAS INVOLVED IN THE SECRETION OF Hcp1 BY T6SS}

Hcp family proteins are secreted via a T6SS-dependent pathway in several bacteria and are detected in bacterial culture supernatants (Mougous etal., 2006; Aschtgen etal., 2010; Mulder et al., 2012; Zhou etal., 2012). Culture supernatants and APEC DE719, DE719 $\Delta$ dotU, DE719C $\Delta$ dotU, and DE719 $\Delta$ T6SS2 cells were tested for Hcp1 and Hcp2 by western blotting using corresponding polyclonal antisera. Hcpl was detected in bacterial lysates of APEC DE719, DE719 $\Delta \operatorname{dotU}, \mathrm{DE719C} \Delta \operatorname{dot} U$, and the culture supernatants of APEC DE719 and DE719C $\Delta$ dotU. No Hcp1 was detected in culture supernatants of DE719 $\Delta \operatorname{dot} U$ or 

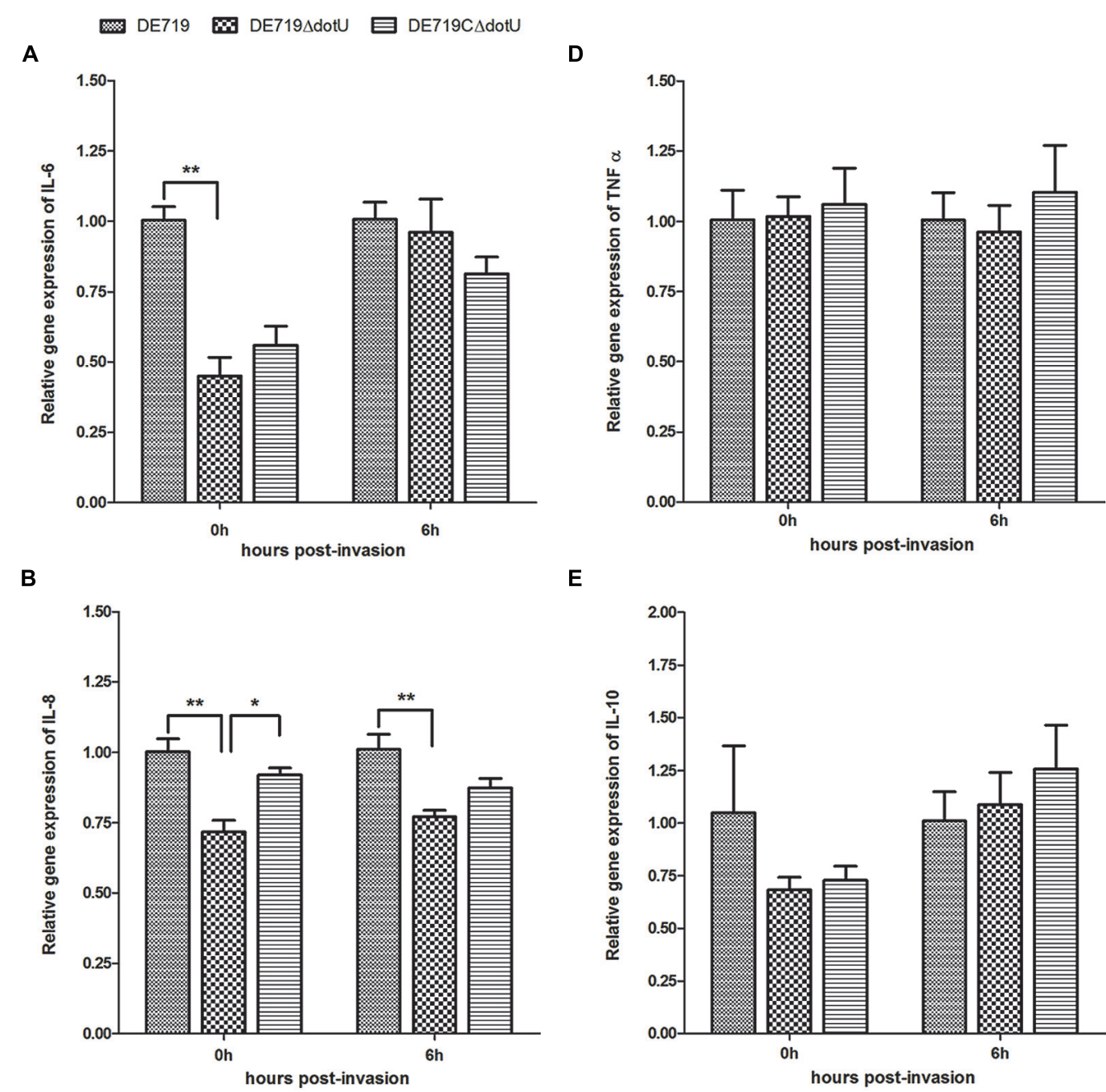

E

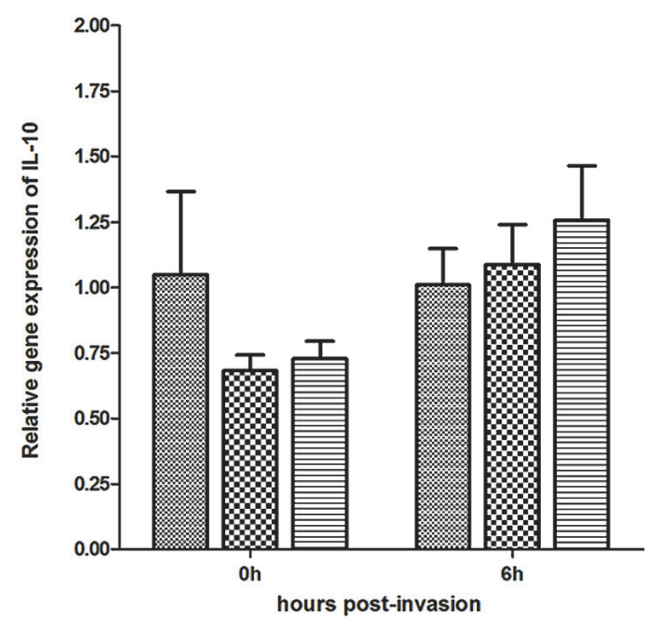

C

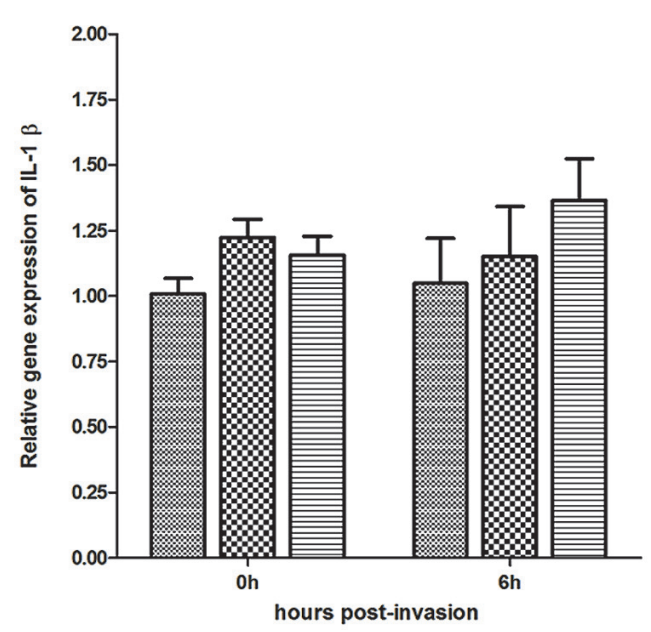

FIGURE 8 | Cytokine expression in the HD-11 cells infected with APEC bacteria. Expression of IL-6 (A), IL-8 (B), IL-1 $\beta$ (C), TNF $\alpha$ (D) and IL-10 (E) in infected HD-11 cells was analyzed by RT-PCR, normalized to $\beta$-actin gene. Samples were calibrated to gene expression in DE719 infected HD-11 cells. Expression of IL-6 and IL-8

was significantly downregulated by 2.2 -fold (IL-6, $0 \mathrm{~h}$ post-invasion), 1.4-fold (IL-8, $0 \mathrm{~h}$ post-invasion), and 1.3-fold (IL-8, $6 \mathrm{~h}$ post-invasion) in cells treated with DE719 $\Delta$ dotU compared with DE719. ${ }^{* *} p<0.01$; ${ }^{*} p<0.05$. Statistical significance analysis was performed by two-way ANOVA. 
A

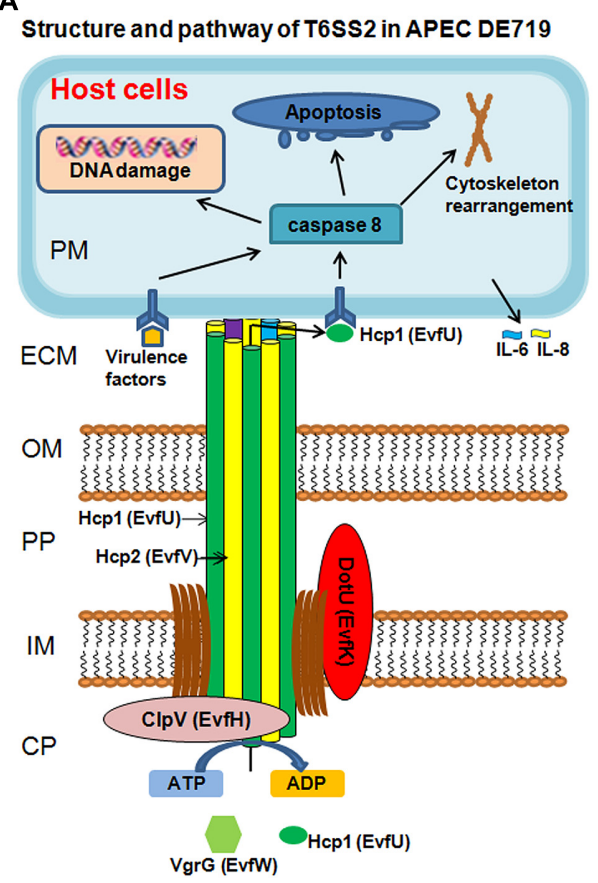

FIGURE 9 | Schematic T6SS2 structure and pathway in APEC dotU mutant. (A) T6SS2 structure and pathway in APEC strains. The channel through the bacterial periplasm is $\mathrm{Hcp} 1, \mathrm{Hcp} 2$, and other proteins that transport effector protein Hcp1 to the ECM. Hcp1 could be recognized by a specific receptor of host cells, leading to cytoskeleton rearrangement, apoptosis, and cytokine release. As the core component, DotU stabilizes the secretion machinery. (B) Deletion
B

Structure and pathway of T6SS2 in APEC DE719 $\Delta$ dotU

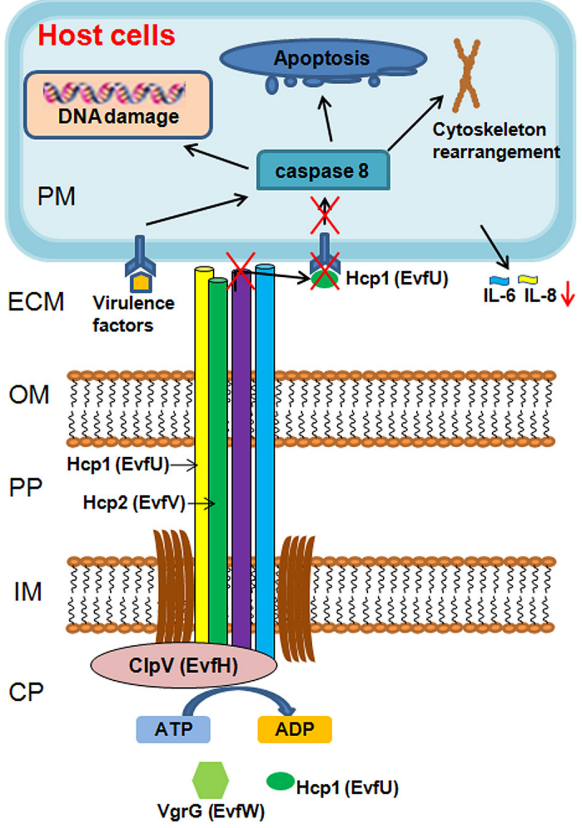

of DotU might lead to defective T6SS2 structure, abolishing secretion of effector protein Hcp1. The defective needle structure might also affect cell aggregation, resistance to normal duck serum, intramacrophage survival and colonization in vitro and in vivo. $\mathrm{CP}$ bacterial cytoplasm; IM, bacterial inner membrane; $\mathrm{PP}$, bacterial periplasm; OM, bacterial outer membrane; ECM, extracellular milieu; and PM, host cell plasma membrane. supernatants or lysates of DE719 $\mathrm{T}$ T6SS2, demonstrating that DotU contributed to secretion of Hcp1 by T6SS2 in APEC DE719 (Figure 7A). Hcp2 protein was detected only in lysates of APEC DE719, DE719 $\Delta$ dotU and DE719C $\Delta$ dotU. No Hcp2 was detected in supernatants or lysates of DE719 $\Delta$ T6SS2 (Figure 7B), which is similar to previous reports of NMEC strain RS218 (Zhou et al., 2012).

\section{DETERMINATION OF THE CYTOKINE EXPRESSION IN APEC INFECTED HD-11 CELLS}

To assess the effects of $\operatorname{dot} U$ deletion on macrophage cytokine expression, HD-11 macrophages were infected with DE719, DE719 $\Delta$ dotU, or DE719C $\Delta$ dotU. Expression of IL-1 $\beta$, IL-6, IL-8, IL-10, and TNF $\alpha$ in infected cells was analyzed at $0 \mathrm{~h}$ and $6 \mathrm{~h}$ post-invasion by qRT-PCR. IL-6 and IL-8 expression was downregulated in cells treated with DE719 $\Delta$ dotU compared with cells treated with DE719. Differences in the expression of IL-6 at $0 \mathrm{~h}$, IL- 8 at $0 \mathrm{~h}$ and $6 \mathrm{~h}$ were significant $(p<0.05$ or $p<0.01$ ). Levels of IL- 6 and IL- 8 were partially restored by expressing DotU in trans (Figure 8). Levels of IL-1 $\beta$, IL-10, and TNF $\alpha$ were not significantly different $(p>0.05)$.

\section{DISCUSSION}

Recently, three distinct T6SS loci were discovered in the APEC genome, distributed as $14.62 \%$ T6SS1, 2.33\% T6SS2, and 0.85\%
T6SS3 in the APEC collections. Comprehensive analysis showed that more than $85 \%$ of T6SSs loci-containing APEC strains belong to the virulent phylogenetic groups D and B2 (Johnson et al., 2006), indicating that T6SSs might contribute to APEC pathogenicity (Ma et al., 2013). Several T6SS proteins including Hcp, VgrG, $\mathrm{IcmF}$, and DotU are important for bacterial pathogenesis. Previous studies showed that APEC T6SS1 is involved in colonization and proliferation in systemic infections and T6SS2 is responsible for intramacrophage survival, cytokine and chemokine release, and host cell apoptosis. However, the function of most T6SS proteins remains unknown (Filloux, 2009; Pukatzki et al., 2009; Silverman et al., 2012).

Our study showed that APEC $\operatorname{dot} U$ was expressed at low levels in LB culture. However, ELISA showed high levels of DotU antibodies in infected ducks, suggesting that APEC DotU interacted with host cells during APEC infection. We examined the contribution of DotU and T6SS2 to APEC pathogenicity. APEC dot $U$ and T6SS2 locus mutant strains and an APEC $\operatorname{dot} U$ complementation strain were constructed. Animal experiments showed that the virulence of $\operatorname{dot} U$ and T6SS2 mutant strains was attenuated compared with the wild-type strain DE719. The complemented strain had recovered virulence. The $\operatorname{dot} U$ and T6SS2 mutant strains did not exhibits growth defects. Thus, we concluded that DotU and T6SS2 were necessary for full virulence of APEC DE719. Colonization is a crucial step for bacterial pathogenesis (Finlay and Falkow, 1997). 
Bacterial infection studies in vitro and in vivo indicated that loss of DotU or T6SS2 resulted in significantly reduced colonization of DF- 1 cells and duck blood and lungs compared to wild-type strain. These results might indicate the reason for attenuated virulence of the mutant strain DE719 $\Delta$ dotU.

Avian pathogenic Escherichia coli infects poultry by initial respiratory tract colonization followed by systemic spread. Serum resistance is an important virulence parameter for APEC infection. Resistance to the bactericidal effects of serum and the capacity of APEC strains to cause septicemia and mortality are correlated (La Ragione and Woodward, 2002; Mellata et al., 2003). Resistance to serum and environmental stress and survival within macrophages are advantages to APEC infection. We examined the survival of APEC in normal duck serum and macrophages. Bactericidal assays demonstrated that resistance to normal duck serum was impaired in the mutant strain DE719 $\Delta \operatorname{dot} U$ (Figure 3). DE719 $\Delta \operatorname{dot} U$ showed a significantly reduced survival rate in macrophage HD11 cells (Figure 4). Resistance defects might be a reason for the reduced bacterial survival of mutant strain DE719 $\Delta$ dotU in hosts.

Hemolysin-coregulated protein family proteins are secreted via a T6SS-dependent pathway and act in bacterial interaction with host cells (Mougous et al., 2006; Aschtgen et al., 2010; Mulder et al., 2012; Zhou etal., 2012). Secretion of the Hcp family proteins

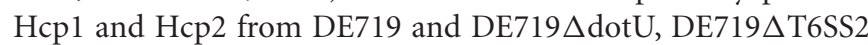
was determined. Hcp1 but not Hcp 2 was secreted by APEC T6SS2, consistent with NMEC RS218 results (Zhou et al., 2012). DotU was essential for secretion of Hcp1 by T6SS2 in APEC DE719. DotU was interacts with $\mathrm{IcmF}$ and prevents degradation of other proteins through an unknown mechanism (Sexton et al., 2004; Zheng and Leung, 2007; Ma et al., 2009; Broms et al., 2012). Deletion of DotU might lead to defects in T6SS2 structural integrity and effector protein Hcpl secretion, although this hypothesis needs further investigation. To eluciate $\mathrm{Hcp} 1$ functions, we generated the mutant strain DE719 $\Delta$ hcp1, which showed adhesion and invasion capacities similar to the wild-type strain DE719 (data not shown), suggesting that Hcpl did not affect bacterial adhesion and invasion, consistent with a previous study (Zhou et al., 2012). Thus, the reduced colonization was due to DotU deletion.

Type VI secretion systems induces cytokine release, actin cytoskeleton rearrangement, and apoptosis in HBMECs. These strategies are exploited by pathogenic bacteria for survival or spread in the host (Zhou et al., 2012). However, our study found no detectable difference in apoptosis in cells stimulated with DE719 or the mutant strain DE719 $\Delta \operatorname{dot} U$ (data no shown). The mutant strain DE719 $\Delta$ dotU induced lower levels of IL-6 and IL-8 gene expression than DE719 (Figure 8), which might be due to the abolition of Hcp1 secretion. IL-6 and IL-8 are important inflammatory mediators in inflammation and leukocyte recruitment and contribute to host immunity or pathogenesis (Zhou et al., 2012). Our data suggested that DotU might affect cytokine production regulating inflammation initiation and cell recruitment, thereby affecting downstream immune response pathways.

In summary, we propose a potential model for DotU in APEC infection (Figure 9) showing the structure and pathway of T6SS2 in wild-type strain DE719 and mutant strain DE719 $\Delta$ dotU. The needle structure of APEC T6SS2 is composed of Hcp1, Hcp2, and other proteins and transports effector protein Hcp1 to the extracellular milieu. Secreted Hcp1 is recognized by a specific receptor of host cells, leading to events including cytoskeleton rearrangement, apoptosis, and cytokine release. The needle structure might increase bacterial capacities of cell aggregation, resistance to normal duck serum, intramacrophage survival and colonization in vitro and in vivo, which are essential for bacterial pathogenesis. Our results suggested that DotU was highly expressed during APEC infection. Deletion of DotU affected Hcp1 secretion and involved in the integrity of the T6SS2 apparatus, resulting in defective function and virulence.

\section{ACKNOWLEDGMENTS}

This work was supported by the funds of Chinese Special Fund for Agro-scientific Research in the Public Interest (201303044), the National Natural Science Foundation of China (81201266, $31370045)$ and The National Basic Fund for Institutes, which is supported by Shanghai Veterinary Research Institute (2013JB05).

\section{REFERENCES}

Antao, E. M., Ewers, C., Gurlebeck, D., Preisinger, R., Homeier, T., Li, G., et al. (2009). Signature-tagged mutagenesis in a chicken infection model leads to the identification of a novel avian pathogenic Escherichia coli fimbrial adhesin. PLoS ONE 4:e7796. doi: 10.1371/journal.pone.0007796

Aschtgen, M. S., Gavioli, M., Dessen, A., Lloubes, R., and Cascales, E. (2010). The SciZ protein anchors the enteroaggregative Escherichia coli type VI secretion system to the cell wall. Mol. Microbiol. 75, 886-899. doi: 10.1111/j.13652958.2009.07028.x

Basler, M., Ho, B. T., and Mekalanos, J. J. (2013). Tit-for-tat: type VI secretion system counterattack during bacterial cell-cell interactions. Cell 152, 884-894. doi: 10.1016/j.cell.2013.01.042

Boyer, F., Fichant, G., Berthod, J., Vandenbrouck, Y., and Attree, I. (2009). Dissecting the bacterial type VI secretion system by a genome wide in silico analysis: what can be learned from available microbial genomic resources? BMC Genomics 10:104. doi: 10.1186/1471-2164-10-104

Broms, J. E., Meyer, L., Lavander, M., Larsson, P., and Sjostedt, A. (2012). DotU and VgrG, core components of type VI secretion systems, are essential for Francisella LVS pathogenicity. PLoS ONE 7:e34639. doi: 10.1371/journal.pone. 0034639

Dai, J., Wang, S., Guerlebeck, D., Laturnus, C., Guenther, S., Shi, Z., et al. (2010). Suppression subtractive hybridization identifies an autotransporter adhesin gene of E. coli IMT5155 specifically associated with avian pathogenic Escherichia coli (APEC). BMC Microbiol. 10:236. doi: 10.1186/1471-2180-10-236

Datsenko, K. A., and Wanner, B. L. (2000). One-step inactivation of chromosomal genes in Escherichia coli K-12 using PCR products. Proc. Natl. Acad. Sci. U.S.A. 97, 6640-6645. doi: 10.1073/pnas.120163297

Davanloo, P., Rosenberg, A. H., Dunn, J. J., and Studier, F. W. (1984). Cloning and expression of the gene for bacteriophage T7 RNA polymerase. Proc. Natl. Acad. Sci. U.S.A. 81, 2035-2039. doi: 10.1073/pnas.81.7.2035

de Pace, F., Nakazato, G., Pacheco, A., De Paiva, J. B., Sperandio, V., and Da Silveira, W. D. (2010). The type VI secretion system plays a role in type 1 fimbria expression and pathogenesis of an avian pathogenic Escherichia coli strain. Infect. Immun. 78, 4990-4998. doi: 10.1128/IAI.00531-10

Dudley, E. G., Thomson, N. R., Parkhill, J., Morin, N. P., and Nataro, J. P. (2006). Proteomic and microarray characterization of the AggR regulon identifies a pheU pathogenicity island in enteroaggregative Escherichia coli. Mol. Microbiol. 61, 1267-1282. doi: 10.1111/j.1365-2958.2006.05281.x

Ewers, C., Janssen, T., Kiessling, S., Philipp, H. C., and Wieler, L. H. (2005). Rapid detection of virulence-associated genes in avian pathogenic Escherichia coli by multiplex polymerase chain reaction. Avian Dis. 49, 269-273. doi: 10.1637/7293102604R

Ewers, C., Li, G., Wilking, H., Kiessling, S., Alt, K., Antao, E. M., et al. (2007). Avian pathogenic, uropathogenic, and newborn meningitis-causing Escherichia coli: how closely related are they? Int. J. Med. Microbiol. 297, 163-176. doi: 10.1016/j.ijmm.2007.01.003 
Filloux, A. (2009). The type VI secretion system: a tubular story. EMBO J. 28, 309-310. doi: 10.1038/emboj.2008.301

Filloux, A., Hachani, A., and Bleves, S. (2008). The bacterial type VI secretion machine: yet another player for protein transport across membranes. Microbiology 154, 1570-1583. doi: 10.1099/mic.0.2008/016840-0

Finlay, B. B., and Falkow, S. (1997). Common themes in microbial pathogenicity revisited. Microbiol. Mol. Biol. Rev. 61, 136-169.

Gao, Q., Xu, H., Wang, X., Zhang, D., Ye, Z., Gao, S., et al. (2013). RfaH promotes the ability of the avian pathogenic Escherichia coli O2 strain E058 to cause avian colibacillosis. J. Bacteriol. 195, 2474-2480. doi: 10.1128/JB.02074-12

Ho, B. T., Dong, T. G., and Mekalanos, J. J. (2014). A view to a kill: the bacterial type VI secretion system. Cell Host Microbe 15, 9-21. doi: 10.1016/j.chom.2013.11.008

Jani, A. J., and Cotter, P. A. (2010). Type VI secretion: not just for pathogenesis anymore. Cell Host Microbe 8, 2-6. doi: 10.1016/j.chom.2010.06.012

Johnson, J. R., Owens, K. L., Clabots, C. R., Weissman, S. J., and Cannon, S. B. (2006). Phylogenetic relationships among clonal groups of extraintestinal pathogenic Escherichia coli as assessed by multi-locus sequence analysis. Microbes Infect. 8, 1702-1713. doi: 10.1016/j.micinf.2006.02.007

Johnson, T. J., Wannemuehler, Y., Johnson, S. J., Stell, A. L., Doetkott, C., Johnson, J. R., et al. (2008). Comparison of extraintestinal pathogenic Escherichia coli strains from human and avian sources reveals a mixed subset representing potential zoonotic pathogens. Appl. Environ. Microbiol. 74, 7043-7050. doi: 10.1128/AEM.01395-08

La Ragione, R. M., and Woodward, M. J. (2002). Virulence factors of Escherichia coli serotypes associated with avian colisepticaemia. Res. Vet. Sci. 73, 27-35. doi: 10.1016/S0034-5288(02)00075-9

Livak, K. J., and Schmittgen, T. D. (2001). Analysis of relative gene expression data using real-time quantitative PCR and the 2(-Delta Delta C(T)) Method. Methods 25, 402-408. doi: 10.1006/meth.2001.1262

Ma, J., Sun, M., Bao, Y., Pan, Z., Zhang, W., Lu, C., et al. (2013). Genetic diversity and features analysis of type VI secretion systems loci in avian pathogenic Escherichia coli by wide genomic scanning. Infect. Genet. Evol. 20, 454-464. doi: 10.1016/j.meegid.2013.09.031

Ma, L. S., Lin, J. S., and Lai, E. M. (2009). An IcmF family protein, ImpLM, is an integral inner membrane protein interacting with ImpKL, and its walker a motif is required for type VI secretion system-mediated Hcp secretion in Agrobacterium tumefaciens. J. Bacteriol. 191, 4316-4329. doi: 10.1128/JB.00029-09

Mellata, M., Dho-Moulin, M., Dozois, C. M., Curtiss, R. III, Brown, P. K., Arne, P., etal. (2003). Role of virulence factors in resistance of avian pathogenic Escherichia coli to serum and in pathogenicity. Infect. Immun. 71, 536-540. doi: 10.1128/IAI.71.1.536-540.2003

Miyata, S. T., Kitaoka, M., Wieteska, L., Frech, C., Chen, N., and Pukatzki, S. (2010). The Vibrio cholerae type VI secretion system: evaluating its role in the human disease cholera. Front. Microbiol. 1:117. doi: 10.3389/fmicb.2010.00117

Mougous, J. D., Cuff, M. E., Raunser, S., Shen, A., Zhou, M., Gifford, C. A., et al. (2006). A virulence locus of Pseudomonas aeruginosa encodes a protein secretion apparatus. Science 312, 1526-1530. doi: 10.1126/science.1128393

Moulin-Schouleur, M., Schouler, C., Tailliez, P., Kao, M. R., Bree, A., Germon, P., et al. (2006). Common virulence factors and genetic relationships between O18:K1:H7 Escherichia coli isolates of human and avian origin. J. Clin. Microbiol. 44, 3484-3492. doi: 10.1128/JCM.00548-06

Mulder, D. T., Cooper, C. A., and Coombes, B. K. (2012). Type VI secretion systemassociated gene clusters contribute to pathogenesis of Salmonella enterica serovar Typhimurium. Infect. Immun. 80, 1996-2007. doi: 10.1128/IAI.06205-11

Pukatzki, S., Ma, A. T., Revel, A. T., Sturtevant, D., and Mekalanos, J. J. (2007). Type VI secretion system translocates a phage tail spike-like protein into target cells where it cross-links actin. Proc. Natl. Acad. Sci. U.S.A. 104, 15508-15513. doi: 10.1073/pnas.0706532104

Pukatzki, S., Ma, A. T., Sturtevant, D., Krastins, B., Sarracino, D., Nelson, W. C., et al. (2006). Identification of a conserved bacterial protein secretion system in Vibrio cholerae using the dictyostelium host model system. Proc. Natl. Acad. Sci. U.S.A. 103, 1528-1533. doi: 10.1073/pnas.0510322103

Pukatzki, S., Mcauley, S. B., and Miyata, S. T. (2009). The type VI secretion system: translocation of effectors and effector-domains. Curr. Opin. Microbiol. 12, 11-17. doi: 10.1016/j.mib.2008.11.010

Records, A. R. (2011). The type VI secretion system: a multipurpose delivery system with a phage-like machinery. Mol. Plant Microbe Interact. 24, 751-757. doi: 10.1094/MPMI-11-10-0262
Rodriguez-Siek, K. E., Giddings, C. W., Doetkott, C., Johnson, T. J., Fakhr, M. K., and Nolan, L. K. (2005a). Comparison of Escherichia coli isolates implicated in human urinary tract infection and avian colibacillosis. Microbiology 151, 2097-2110. doi: 10.1099/mic.0.27499-0

Rodriguez-Siek, K. E., Giddings, C. W., Doetkott, C., Johnson, T. J., and Nolan, L. K. (2005b). Characterizing the APEC pathotype. Vet. Res. 36, 241-256. doi: 10.1051/vetres:2004057

Rosales-Reyes, R., Skeldon, A. M., Aubert, D. F., and Valvano, M. A. (2012). The type VI secretion system of Burkholderia cenocepacia affects multiple Rho family GTPases disrupting the actin cytoskeleton and the assembly of NADPH oxidase complex in macrophages. Cell. Microbiol. 14, 255-273. doi: 10.1111/j.1462-5822.2011.01716.x

Saier, M. H. (2006). Protein secretion and membrane insertion systems in gram-negative bacteria. J. Membr. Biol. 214, 75-90. doi: 10.1007/s00232-0060049-7

Schlieker, C., Zentgraf, H., Dersch, P., and Mogk, A. (2005). ClpV, a unique Hsp100/Clp member of pathogenic proteobacteria. Biol. Chem. 386, 1115-1127. doi: 10.1515/BC.2005.128

Sexton, J. A., Miller, J. L., Yoneda, A., Kehl-Fie, T. E., and Vogel, J. P. (2004). Legionella pneumophila DotU and $\mathrm{IcmF}$ are required for stability of the Dot/Icm complex. Infect. Immun. 72, 5983-5992. doi: 10.1128/IAI.72.10.5983-599 2.2004

Shrivastava, S., and Mande, S. S. (2008). Identification and functional characterization of gene components of type VI secretion system in bacterial genomes. PLoS ONE 3:e2955. doi: 10.1371/journal.pone.0002955

Silverman, J. M., Brunet, Y. R., Cascales, E., and Mougous, J. D. (2012). Structure and regulation of the type VI secretion system. Annu. Rev. Microbiol. 66, 453-472. doi: 10.1146/annurev-micro-121809-151619

Studier, F. W., and Moffatt, B. A. (1986). Use of bacteriophage T7 RNA polymerase to direct selective high-level expression of cloned genes. J. Mol. Biol. 189, 113-130. doi: 10.1016/0022-2836(86)90385-2

Tivendale, K. A., Logue, C. M., Kariyawasam, S., Jordan, D., Hussein, A., Li, G., et al. (2010). Avian-pathogenic Escherichia coli strains are similar to neonatal meningitis $E$. coli strains and are able to cause meningitis in the rat model of human disease. Infect. Immun. 78, 3412-3419. doi: 10.1128/IAI. 00347-10

Wang, S., Meng, Q., Dai, J., Han, X., Han, Y., Ding, C., et al. (2014). Development of an allele-specific PCR assay for simultaneous sero-typing of avian pathogenic Escherichia coli predominant O1, O2, O18 and O78 strains. PLoS ONE 9:e96904. doi: 10.1371/journal.pone.0096904

Wang, S., Niu, C., Shi, Z., Xia, Y., Yaqoob, M., Dai, J., et al. (2011a). Effects of ibeA deletion on virulence and biofilm formation of avian pathogenic Escherichia coli. Infect. Immun. 79, 279-287. doi: 10.1128/IAI.00821-10

Wang, S., Xia, Y., Dai, J., Shi, Z., Kou, Y., Li, H., et al. (2011b). Novel roles for autotransporter adhesin AatA of avian pathogenic Escherichia coli: colonization during infection and cell aggregation. FEMS Immunol. Med. Microbiol. 63, 328338. doi: 10.1111/j.1574-695X.2011.00862.X

Wang, S., Shi, Z., Xia, Y., Li, H., Kou, Y., Bao, Y., et al. (2012). IbeB is involved in the invasion and pathogenicity of avian pathogenic Escherichia coli. Vet. Microbiol. 159, 411-419. doi: 10.1016/j.vetmic.2012.04.015

Wang, Y., and Kim, K. S. (2002). Role of OmpA and IbeB in Escherichia coli K1 invasion of brain microvascular endothelial cells in vitro and in vivo. Pediatr. Res. 51, 559-563. doi: 10.1203/00006450-200205000-00003

Wu, H. Y., Chung, P. C., Shih, H. W., Wen, S. R., and Lai, E. M. (2008). Secretome analysis uncovers an Hcp-family protein secreted via a type VI secretion system in Agrobacterium tumefaciens. J. Bacteriol. 190, 2841-2850. doi: 10.1128/JB. 01775-07

Zheng, J., and Leung, K. Y. (2007). Dissection of a type VI secretion system in Edwardsiella tarda. Mol. Microbiol. 66, 1192-1206. doi: 10.1111/j.13652958.2007.05993.x

Zhou, Y., Tao, J., Yu, H., Ni, J., Zeng, L., Teng, Q., et al. (2012). Hcp family proteins secreted via the type VI secretion system coordinately regulate Escherichia coli K1 interaction with human brain microvascular endothelial cells. Infect. Immun. 80, 1243-1251. doi: 10.1128/IAI.05994-11

Zhuge, X., Wang, S., Fan, H., Pan, Z., Ren, J., Yi, L., et al. (2013). Characterization and functional analysis of AatB, a novel autotransporter adhesin and virulence factor of avian pathogenic Escherichia coli. Infect. Immun. 81, 2437-2447. doi: 10.1128/IAI.00102-13 
Zusman, T., Feldman, M., Halperin, E., and Segal, G. (2004). Characterization of the $i \mathrm{cmH}$ and $i \mathrm{cmF}$ genes required for Legionella pneumophila intracellular growth, genes that are present in many bacteria associated with eukaryotic cells. Infect. Immun. 72, 3398-3409. doi: 10.1128/IAI.72.6.3398-340 9.2004

Conflict of Interest Statement: The authors declare that the research was conducted in the absence of any commercial or financial relationships that could be construed as a potential conflict of interest.

Received: 23 August 2014; accepted: 20 October 2014; published online: 07 November 2014
Citation: Wang S, Dai J, Meng Q, Han X, Han Y, Zhao Y, Yang D, Ding C and Yu S (2014) Dot $U$ expression is highly induced during in vivo infection and responsible for virulence and Hcpl secretion in avian pathogenic Escherichia coli. Front. Microbiol. 5:588. doi: 10.3389/fmicb.2014.00588

This article was submitted to Infectious Diseases, a section of the journal Frontiers in Microbiology.

Copyright (c) 2014 Wang, Dai, Meng, Han, Han, Zhao, Yang, Ding and Yu. This is an open-access article distributed under the terms of the Creative Commons Attribution License (CC BY). The use, distribution or reproduction in other forums is permitted, provided the original author(s) or licensor are credited and that the original publication in this journal is cited, in accordance with accepted academic practice. No use, distribution or reproduction is permitted which does not comply with these terms. 